\title{
As Diretivas Antecipadas de Vontade em Transtornos Mentais como Reflexo do Direito Fundamental à Liberdade: Debates Necessários
}

\author{
Janaína Reckziegel \\ Pós-Doutoranda pela Universidade Federal de Santa Catarina - UFSC. Professora e \\ Pesquisadora do Programa de Pós-Graduação em Direito da Universidade do Oeste \\ de Santa Catarina - UNOESC. E-mail: janaina.reck@gmail.com
}

\section{Orides Mezzaroba}

Professor do Programa de Pós-Graduação em Direito da Universidade Federal de Santa Catarina. E-mail: oridesmezza@gmail.com

\section{Beatriz Diana Bauermann Coninck}

Mestre em Direito pelo Programa de Pós-Graduação Stricto Sensu da Universidade do Oeste de Santa Catarina - UNOESC. E-mail: mestrebeatriz123@hotmail.com

\begin{abstract}
Resumo: Este artigo visa investigar a viabilidade concreta da adesão ao instrumento das diretivas antecipadas psiquiátricas de vontade, reconhecidamente um direito fundamental, pelos pacientes acometidos de transtorno mental grave, mas não em estado emergencial. Para tanto serão discutidas noções gerais sobre as diretivas antecipadas de vontade para então, no segundo item, adentrar no estudo das diretivas psiquiátricas antecipadas de vontade e, no terceiro tópico, discorrer sobre a viabilidade das diretivas antecipadas psiquiátricas. A partir da investigação realizada por meio do método dedutivo de abordagem qualitativa com pesquisa em referências nacionais, abrangendo estudos empíricos, descobriu-se que a dificuldade em identificar diagnóstico das patologias mentais pelos médicos e a problemática da adesão ao tratamento farmacológico pela pessoa acometida de transtorno mental, são causas para a recorrência de recidivas das crises, dos internamentos e da cronicidade dos transtornos, e, por consequência, da rejeição das disposições de vontade dos pacientes pelos médicos.
\end{abstract}

Palavras-chave: Direito fundamental. Diretivas antecipadas psiquiátricas de vontade. Pacientes com transtornos mentais graves não emergenciais.

\section{UNIVERSIDADE FEDERAL DA PARAÍBA}

João Pessoa, Programa de Pós-Graduação em Ciências Jurídicas 


\title{
As Diretivas Antecipadas de Vontade em Transtornos Mentais como Reflexo do Direito Fundamental à Liberdade: Debates Necessários
}

\author{
Janaína Reckziegel
}

Orides Mezzaroba

Beatriz Diana Bauermann Coninck

\section{INTRODUÇÃO}

Existem situações em que a morte é o desfecho do processo natural do viver. Em outras, a abreviação da vida pode ocorrer devido a um trauma físico, a uma parada cardiorrespiratória, ou em razão de enfermidade incurável. Há pacientes que padecem acamados em estado vegetativo por anos, há outros que já estão próximos da terminalidade de vida quando se define o diagnóstico, restando recorrer a tratamentos e terapias que apenas podem oferecer melhor qualidade de vida, dentro do tempo que ainda resta, ou postergar a sobrevida.

As tomadas de decisão envolvendo procedimentos médicos naquelas ocasiões dão ensejo, muitas vezes, a conflitos internos, quando necessária e possível o julgamento do próprio doente, e a atritos familiares, quando o interessado está debilitado para decidir. Estes se veem obrigados a definir se o procedimento médico deve ou não ocorrer e nem sempre atendem a vontade do enfermo naquela 
As Diretivas Antecipadas de Vontade em Transtornos Mentais...

situação.

Em vista disso, com o objetivo de valorizar a autonomia e a autodeterminação do paciente, nos processos de tomada de decisão relativamente à sua saúde, e evitar mais esses aborrecimentos, as diretivas antecipadas de vontade constituem um instrumento médico e jurídico, cujas previsões antecipadamente registradas pelo próprio possível futuro doente, capaz de trazer mais conforto e tranquilidade para todos os envolvidos no processo de tratamento, não restando essa difícil tarefa apenas ao médico. Em verdade, as diretivas asseguram o exercício de manifestação de vontade do paciente e a autonomia em suas escolhas, quando em quadro de irreversibilidade no que se relaciona a sua saúde (XEREZ; PINTO, 2018).

Maiores dificuldades são encontradas para pacientes com transtornos mentais graves que não se encontrem em situações emergenciais que garantem ao médico o dever de evitar danos à saúde e à vida do paciente, independentemente da vontade deste ou de sua família. Esse é um ponto nebuloso para a delimitação da autonomia do paciente e, muitas vezes, uma barreira intransponível para o médico.

Em vista disso, o objetivo deste artigo é apresentar as diretivas antecipadas de vontade com os seus conceitos e regras gerais bem como as diretivas antecipadas psiquiátricas, e analisar a viabilidade das diretivas antecipadas psiquiátricas para pacientes com transtorno mental severo que não estejam em situação de urgência ou emergência. Para tanto, utilizou-se da metodologia dedutiva de abordagem qualitativa com pesquisa em referências nacionais abrangendo estudos empíricos.

$\mathrm{O}$ artigo estrutura-se da seguinte forma: inicialmente apresenta-se um conceito geral sobre as diretivas antecipadas de vontade, entendendo que as mesmas subdividem-se em testamento vital e mandato duradouro. Na sequência, analisa-se a aplicação histórica das diretivas antecipadas no Brasil, apresentando fatos e legislações que tem sido base da utilização desses instrumentos no país, dando especial destaque a Resolução do Conselho Federal de 
Medicina $\mathrm{n}^{0}$ 1995/2012. Após discute-se a respeito das diretivas antecipadas no que se relaciona ao paciente psiquiátrico, abordandose a questão da capacidade psicológica e aquela prevista legalmente. Por fim, discute-se a respeito da viabilidade concreta das diretivas psiquiátricas de vontade para pacientes com transtornos mentais severos em situações não emergenciais.

\section{CONTEXTUALIZANDO AS DIRETIVAS ANTECIPADAS DE VONTADE}

A diretiva antecipada de vontade (DAV) é um documento em que constam as vontades de um indivíduo para possíveis situações antes do óbito, em que este se manifesta em relação às condutas a serem tomadas em caso de incapacidade. O paciente pode previamente exprimir seus desejos em relação ao tratamento de saúde que será utilizado em seus momentos finais de existência. Nas diretivas, o paciente manifesta o direito de exercer livremente o Princípio da Autonomia, baseado no fundamento da Dignidade Humana (GOUVEIA, 2017). Além disso, a diretiva antecipada também serve como documento de defesa para o médico, em caso de responsabilização pelo uso de determinados tratamentos e cuidados escolhidos pelo paciente (GAUW et al., 2017).

No entanto, é necessário que se esclareça que, trata-se de um gênero de manifestação de vontade, que é constituído pelo testamento vital e o mandato duradouro. Nesse sentido, verifica-se que o testamento vital é realizado com o paciente em estado mental preservado, com capacidade de redigir suas vontades em relação aos cuidados, tratamentos e procedimentos para quando encontrar-se em 
situação de cuidados paliativos ou doença de prognóstico reservado. Deve ser redigido com auxilio de um médico de confiança do paciente, que terá como função orientá-lo em relação aos termos técnicos, sem influenciá-lo em suas decisões. Em relação ao mandato duradouro, trata-se de nomeação de pessoa de confiança do paciente, que deverá ser consultada pelos médicos, quando necessário tomar alguma decisão em relação ao tratamento ou para esclarecer alguma dúvida em relação ao testamento vital, quando isto for impossível ao paciente (GAUW et al., 2017).

Historicamente o processo de aceitação das diretivas antecipadas de vontade no Brasil tem sido lento e progressivo. As primeiras iniciativas foram vistas no âmbito da Associação Brasileira de Cuidados Paliativos, fundada em outubro de 1997, visando à implantação e à divulgação dos cuidados paliativos por meio de pesquisas e educação (SERRANO, 2012, p. 7). Já em 17 de março de 1999, o Estado de São Paulo, através do inciso XXIII, do artigo $2^{\circ}$, da Lei Estadual $n^{0}$ 10.241, preocupou-se com os direitos dos usuários do serviço de saúde de recusar tratamentos extraordinários ou dolorosos para buscar o prolongamento da vida de pacientes terminais sem chances de cura.

A Lei foi sancionada pelo Governador Mário Covas, que vinha sofrendo de carcinomatose meningea (tumor na bexiga) quando aprovou a norma, vindo a falecer em 2001. O caso do ex-governador de São Paulo inaugurou a temática da ortotanásia no Brasil, eis que ele preferiu passar os seus últimos dias ao lado da família, em casa, recebendo cuidados paliativos com medicações para minimizar a dor, em vez de se submeter a intervenções invasivas e à internação (MANSUR; MARQUES, 2011, p. 1-3; MUSTAFA, 2010)1.

1 O papa João Paulo II também escolheu suspender as intervenções para sua sobrevida e optou por morrer em casa, no Palácio Apostólico, no Vaticano, sendo medicado para dor de artrite e Mal de Parkinson, vindo a falecer em 2 de abril de 2005. Da mesma forma a decisão do Tribunal de Justiça do Estado do Rio Grande do Sul, a Apelação Cível no 70042509562 , em que o filho da paciente incapaz (que sofria de insuficiência renal descompensada) pleiteava a recusa da hemodiálise na mãe, uma vez que do procedimento pudesse incorrer risco de vida. O Tribunal acatou o pedido entendendo que o filho estava acolhendo o desejo da mãe com base na Resolução $n^{0}$ 1.805/2006. Nesse sentido também no mesmo Tribunal, em 20 de 
Em novembro de 2006, a Câmara Técnica sobre Terminalidade da Vida do Conselho Federal de Medicina editou a Resolução $\mathrm{n}^{0} 1.805$, que permitiu ao médico restringir ou suspender tratamentos que apenas prolonguem a sobrevida de pacientes terminais acometidos por enfermidade grave e incurável, devendo, contudo, prestar cuidados necessários no sentido de minimizar a dor e o sofrimento, respeitando-se a vontade do paciente ou de seu representante legal (art. $1^{\circ}$ ). A referida Norma previu que toda assistência precisa almejar o bem-estar físico, social, psíquico e espiritual, e, em caso de preferência, receber alta hospitalar. A Resolução ampara o direito de informação do paciente, ou do representante legal, a respeito das terapias adequadas à doença (art. $1^{\mathrm{o}}, \S 1^{\mathrm{o}}$ ), bem como de sua declaração constar em prontuário (art. $1^{\mathrm{o}}$, $\left.\S 2^{\mathrm{o}}\right)$.

O Código de Ética Médica, em vigor desde 22 de março de 2010, sobre a terminalidade da vida, reafirmou o conteúdo da Resolução $\mathrm{n}^{\mathrm{o}}$ 1.805/2006. Nos casos clínicos irreversíveis e terminais, a disciplina que procedimentos de diagnose e terapias “desnecessárias" devem ser evitados, preferindo-se cuidados paliativos (capítulo 1, XXII). O Código vedou ao médico abreviar a vida do paciente, mesmo contrariando o pedido deste ou de seu representante legal (capítulo V, art. 41). Se o paciente se encontrar em condição terminal de vida, o médico não pode empregar condutas obstinadas e inúteis recorrendo sempre aos cuidados paliativos, sem, contudo, deixar de levar em consideração a vontade do paciente ou de seu representante legal (capítulo 1, XXII).

A importância da temática sobre a terminalidade da vida ganhou status de princípio fundamental no cenário jurídico, e a Resolução $\mathrm{n}^{\mathrm{O}} 1.805$ foi questionada pelo Ministério Público Federal

novembro de 2013, na Apelação Cível $n^{0}$ 70054988266, em que o paciente "usuário-morador do Hospital Colônia Itapuã e ex-hanseniano", recusou-se ao procedimento cirúrgico de amputação do pé em necrose progressiva. O Juízo entendeu que ele estava capaz para decidir e tinha autonomia e que a situação se ajustava à ortotanásia. O Tribunal fundamentou-se na Resolução ${ }^{\circ}{ }^{\circ}$ 1.805 do CFM, no princípio da dignidade humana, no direito à vida (e não dever de viver), na Resolução no ${ }^{0}$ 1.995/2012 e no artigo 15 do Código Civil. 
do Distrito Federal, na Ação Civil Pública $n^{0}$ ooo11039-862013.4.013500, em 2008, alegando a incompetência do Conselho Federal de Medicina para normatizar condutas delituosas. O Conselho, diante da ausência legislativa, apressadamente, publicou o Código de Ética Médica em 2009², em vigor desde o9 de agosto de 2012, prevendo as diretivas antecipadas de vontade através da Resolução $\mathrm{n}^{0} 1995$.

A Resolução $n^{0} 1995$ busca valorizar a autonomia do paciente, através das diretivas antecipadas de vontade, como forma de se posicionar frente à utilização de instrumentos tecnológicos limitados em prolongar a vida e o sofrimento de pacientes terminais. São intervenções desproporcionais que não geram benefícios ou perspectiva de reabilitação. Diferentemente da Resolução $\mathrm{n}^{0}$ 1.805/2006, a de 2012 sugere o alargamento de abrangência das diretivas, não limitada a beneficiar apenas pacientes terminais, trazendo para o contexto o problema em torno dos pacientes em estado vegetativo persistente, que não são reconhecidos como pessoas terminais.

De acordo com Pittelli (2013, p. 23), o objetivo da Resolução $n^{0} 1.995$ foi evoluir na abrangência de beneficiários, de forma a complementar a Resolução $\mathrm{n}^{0}$ 1.805/20063, cuja disciplina se

\footnotetext{
2 Entre os princípios fundamentais a serem respeitados pelo médico, no capítulo I, item VI, o Código de Ética Médica (2013), prima-se pela não utilização de seus conhecimentos técnicos de forma a provocar sofrimento físico ou moral no paciente, ou que permita ou acoberte qualquer tentativa contra a dignidade e integridade deste. Por outro lado, o item VIII repudia a renúncia do médico de sua liberdade profissional, vedando restrições ou imposições que lhe dificulte ou prejudique a eficiência e correção laboral. O Código ainda estabelece, no Item XVI, que o médico escolherá os meios de diagnóstico e de tratamento, desde que em benefício do paciente e sempre no interesse e bem-estar deste (XVII). A escolha do paciente será respeitada diante de procedimentos diagnósticos e terapêuticos, contanto que sejam ajustados ao reconhecimento científico e conformes aos "ditames de consciência" do médico e às disposições legais (XXI). Ademais, em casos de irreversão clínica e de terminalidade, o médico evitará a submissão do paciente a procedimentos diagnósticos e terapêuticos desnecessários e oferecerá cuidados paliativos adequados.

3 Permite o artigo $1^{\circ}$ que o médico limite ou suspenda tratamentos e procedimentos que prolonguem a vida do enfermo que se encontre em fase terminal de doença grave ou incurável, respeitando a vontade do doente ou de seu representante legal. Pittelli e Oliveira (2009, p. 37) alertam que essa norma é restrita apenas aos casos terminais da doença e não inclui a eutanásia. Ela também possui uma pretensão permissiva e não obrigatória, dando margem de atuação ao médico. Ela exige a
} 
manteve no teor permissivo e ético das medidas paliativas. A primeira normativa almejou obrigar o médico a atender as diretivas antecipadas do paciente, reiterando a noção de que a eliminação das terapias obstinadas e a opção pelos cuidados paliativos constituem parâmetros éticos.

É importante salientar, contudo, a relação de alteridade e de corresponsabilidade ética que permeiam a interação médicopaciente. É justamente por isso que as normas éticas proíbem a eutanásia e o suicídio assistido, que seriam instrumentos utilizados para obrigar o médico a executar seus pares. O objetivo dos cuidados paliativos é deixar fluir o curso vital normalmente, limitando-se a oferecer melhor qualidade de vida enquanto ainda vivo.

A mútua divisão de responsabilidades reflete a autonomia médica (materializada na ideia de beneficência) e do paciente (ou de familiares deste ou responsável legal), muito embora pareça difícil que o paciente possa deter uma autonomia plena até mesmo pela sua condição de dupla vulnerabilidade: de doente e de desconhecer a técnica médica.

$\mathrm{Na}$ prática, muitos aspectos relevantes interferem tornando difícil a adesão pelas diretivas antecipadas de vontade. Em primeiro lugar, é necessário que a pessoa ainda saudável e capaz tenha uma previsão das possíveis enfermidades que possam acometê-la no futuro. Já, de antemão, é necessário que o indivíduo tenha certo conhecimento técnico, uma determinada bagagem informativa sobre moléstias, de um modo geral, e seus respectivos tratamentos disponíveis. Além disso, é imperativo que a pessoa esteja capaz de decidir de forma autônoma e livre no momento em que adere ao documento.

Ainda no ano de 2012, a inatividade legislativa sobre o assunto

coleta do esclarecimento consentido do paciente, o registro em prontuário e a obrigação de oferecer ao paciente, ou familiar deste, a oportunidade de consultar outra opinião médica. O interesse do Conselho foi o de transmitir aos médicos que essa conduta não caracteriza abandono. A Resolução não explicitou a expressão "ortotanásia" por receio da herança, em parte simbólica, que o termo herdou da "eutanásia”. 
motivou os civilistas a se manifestarem na V Jornada de Direito Civil, ocasião em que publicaram o Enunciado 528, que por sua vez faz referência aos artigos 1.729, parágrafo único, e 1.857, ambos do Código Civil, validando a declaração de vontade, o "testamento vital", como documento autêntico especificamente para dispor sobre as preferências de tratamento de saúde quando a pessoa estiver incapaz de expressar a própria vontade.

Existe diferenciação entre as diretivas antecipadas de vontade e as declarações prévias, muito embora o Conselho Federal de Medicina as tenha tratado como sinônimas4. Enquanto as declarações prévias produzem efeitos somente quando o paciente se encontrar em situação de incapacidade que torna inviável a sua manifestação de vontade, nas diretivas antecipadas de vontade, por incluírem o mandato vindouro, são consideradas as informações proferidas pelo representante do paciente incapaz, caso este tenha designado previamente, salvo se as diretivas antecipadas de vontade não estiverem de acordo com as determinações do Código de Ética Médica.

A Resolução não exige obrigatoriamente que os desejos do representante sejam atendidos, mas que tão somente sejam levados em consideração (CFM, art. $2^{\circ}$, $\S 1^{\circ}$ e $\S 2^{\circ}$, Resolução $\left.n^{0} 1.995 / 2012\right)$. Somado ao limite ético, a autonomia do paciente também é limitada pelo ordenamento jurídico brasileiro, pela consciência do médico e pela insegurança deste frente a processos judiciais futuros.

$\mathrm{Na}$ Resolução $\mathrm{n}^{0}$ 1.995/2012, houve emprego do termo, "diretiva", exatamente conforme a tradução exigida no sentido de indicar, orientar e instruir e não obrigar, de maneira que o médico não pode ser compelido a atuar conforme as diretivas, devendo

\footnotetext{
4 Por ser o representante de uma categoria diretamente vinculada à situação, o Conselho parece transmitir a ideia de valor declaratório das disposições de vontade, contudo, procurando convencer os médicos a aceitá-las. Isso é perceptível na exposição de motivos da Resolução ${ }^{0}{ }^{1.995 / 2012}$ em que o órgão revelou a resistência dos médicos em recepcionar as diretivas, que somados representam a sua maioria. Outro problema para adoção das disposições de vontade seria a dificuldade de comunicação que atinge quase a totalidade dos pacientes terminais, havendo a necessidade de contar com as informações de terceiros como interlocutores da vontade do paciente.
} 
prevalecer a ideia de alteridade e não a sobreposição de um desejo sobre o outro. A palavra "antecipada" simboliza antecipação, algo prévio, adiantado a algum evento não ocorrido e, vontade remete à noção de externar um desejo de forma capaz e tomar uma decisão de acordo com o interesse individual. As diretivas antecipadas de vontade são medidas aplicadas em vida e o sentido semântico do vocábulo "will" é interpretado como desejo, vontade, escolha consciente (ALVES; FERNANDES; GOLDIM, 2012, p. 359-360).

As disposições do paciente se sobrepõem aos desejos dos familiares ou sobre qualquer parecer não médico e devem ser registradas no prontuário médico do paciente, caso não existam manifestação prévias em cartório. Se, além de inexistirem as declarações de vontade do paciente e de representante designado, não houver familiares à disposição, ou, havendo dissenso entre estes últimos, o médico poderá consultar o Comitê de Bioética institucional e, na ausência deste, a Comissão de Ética Médica hospitalar ou o Conselho Regional e Federal de Medicina, de modo a respaldar sua decisão em face de situação ética conflituosa (Resolução $\mathrm{n}^{0}$ 1.995/2012, art. $2^{\circ}, \S 3^{\circ}, \S 4^{\circ}$ e $\S 5^{\circ}$ ).

A adesão aos documentos de manifestação de vontade tem sido progressiva desde que o Conselho Federal de Medicina publicou a Resolução das diretivas, de acordo com os dados do Colégio Notarial do Brasil - Seção São Paulo, nas publicações de 26 de janeiro de 2015 e 30 de novembro de 2015. Constataram-se as seguintes estatísticas: no ano de 2009, havia o registro de apenas 26 Testamentos Vitais, acrescendo, em 2011, para 68. Em 2012, foram registradas 167 escrituras. Em 2013, foram elaborados 477 documentos após a Resolução entrar em vigor. No ano de 2014, foram lavradas 549 escrituras, um aumento de $2000 \%$ no número de testamentos vitais até janeiro de 2015. E, ao longo do ano de 2015, foram realizados 552 testamentos vitais5.

5 Em outubro de 2013, a Corregedoria-Geral de Justiça do Estado de Minas Gerais, ao codificar os atos normativos relativamente aos serviços notariais e de registro, no Provimento $n^{0}$ 260/2013, normatizou as Declarações Antecipadas de Vontade, 
O Estado de São Paulo tem levantado as estatísticas, seguido do Mato Grosso e do Rio Grande do Sul. O diretor do Colégio Notarial do Brasil de São Paulo, Andrey Guimarães Duarte, atribui esse crescente aumento de documentos à elevação da expectativa de vida dos brasileiros que desemboca em doenças incapacitantes e neurodegenerativas (Alzheimer e Parkinson), somadas à facilidade informacional6 (CNBSP, 2015).

Entretanto, as dificuldades esbarram na coleta de manifestação de vontade de pacientes psiquiátricos, devido à incapacidade própria de suas enfermidades, deixando-os à margem do acesso do seu direito fundamental de decidir sobre tratamento médico. O consentimento informado do paciente é um instrumento material, reconhecidamente um direito fundamental, de valorização e respeito pela dignidade da pessoa humana.

nos artigos 259, 260 e 261, todos no capítulo X, com vistas à lavratura pública das diretrizes antecipadas (ou Declaração Antecipada de Vontade).

${ }^{6}$ O Instituto Brasileiro de Direito de Família noticiou, em 11 de agosto de 2015, os dez motivos para se efetivar uma diretiva antecipada de vontade (testamento vital): a) proteção à dignidade por meio da escolha prévia do paciente quanto ao tipo da terapia médica a que deseja se submeter; b) tranquilidade, pois as Diretivas não antecipam a morte por meio da eutanásia, e sim assegura o seu transcurso natural ou garante a postergação da morte em conformidade com a vontade do paciente; c) o respeito à vontade do paciente registrada no documento; d) paz diante do conforto à família e ao próprio paciente no momento de sofrimento em que este não mais será capaz de se manifestar; e) segurança para o médico no cumprimento integral da vontade do paciente evitando que o médico seja pressionado pelos familiares do doente; f) autonomia ao requerente, contanto que esteja lúcido e capaz de manifestar o destino que pretende para o próprio corpo; g) lealdade do procurador responsável quando tiver de revelar ao médico e aos familiares do outorgante as escolhas antecipadas; h) a revogabilidade do documento se porventura o requerente mudar sua opinião enquanto ainda estiver lúcido; i) perpetuidade já que as diretivas permanecem arquivadas em cartório disponibilizando uma segunda via a qualquer tempo; e j) liberdade para escolher o tabelião de notas seja qual for o domicílio da parte. 


\section{DIRETIVAS ANTECIPADAS PSIQUIÁTRICAS DE VONTADE}

Antes de iniciar a abordagem específica a respeito das Diretivas Antecipadas de Vontade é necessário situar a questão do paciente psiquiátrico, já que este é objeto do estudo em questão. Os transtornos psiquiátricos ou transtornos mentais são classificados de acordo com o Manual Diagnóstico e Estatístico de Transtornos Mentais (DSM), elaborado pela American Psychiatric Association, que está atualmente em sua quinta edição. Tal manual conta com edições há mais de 60 anos e tem como objetivo ser uma referência para a prática clínica na área de saúde mental (ASSOCIAÇÃO AMERICANA DE PSQUIATRIA, 2014, p.41).

Este manual, o DSM 5, define transtorno mental como uma síndrome caracterizada por perturbação clinicamente significativa na cognição, na regulação emocional ou no comportamento de uma pessoa, refletindo uma disfunção nos processos psicológicos, biológicos ou de desenvolvimento relacionados ao funcionamento mental. Os transtornos se relacionam a sofrimento ou incapacidades significativos e afetam atividades sociais, profissionais, entre outras. O manual apresenta uma gama de transtornos psiquiátricos, a saber: transtornos de neurodesenvolvimento; espectro da esquizofrenia e outros transtornos psicóticos; transtornos bipolares e relacionados; transtornos depressivos; transtornos de ansiedade; transtornos obsessivo-compulsivos e relacionados; transtornos relacionados a traumas e estressores; transtornos dissociativos; transtornos de sintomas somáticos e relacionados; transtornos alimentares; transtornos de eliminação; transtornos de sono-vigília; disfunções sexuais; disforia de gênero; transtorno disruptivo, do controle de impulsos e da conduta; transtornos relacionados a substâncias e transtornos aditivos; transtornos neurocognitivos; transtornos de personalidade; transtornos parafílicos; outros transtornos mentais; transtornos do movimento induzidos por medicamentos e outros 
As Diretivas Antecipadas de Vontade em Transtornos Mentais...

efeitos adversos de medicamentos; e outras condições que podem ser foco de atenção clínica (ASSOCIAÇÃO AMERICANA DE PSIQUIATRIA, 2014, p. 20 e 27).

A partir da verificação do DSM, percebe-se que a questão do transtorno psiquiátrico é complexa, podendo um mesmo paciente se enquadrar em mais de um diagnóstico de transtorno mental ou não apresentar todos os critérios diagnósticos de determinado transtorno, mas necessitar de tratamento ou cuidados. Considerando esta complexidade e entendendo que estes pacientes ao manifestarem-se em relação às diretivas antecipadas de vontade, especialmente no testamento vital, devem estar com a capacidade mental preservada é necessário que se avalie a questão da autonomia psicológica. Afinal de contas, estes indivíduos teriam condições de expressar sua última vontade em relação aos tratamentos e cuidados em seus momentos finais de vida?

Para responder a esta questão, inicialmente é necessário entender o conceito e os elementos da capacidade psicológica. Para Miller (2004, p. 246) é possível identificar três elementos no que tange à capacidade psicológica da autonomia: atuação, independência e racionalidade. A primeira diz respeito à autoconsciência dos próprios desejos (inclinações, antipatias, necessidades e correlatos) e ao atuar sobre eles. O que difere as coisas e um animal não humano de uma pessoa é a capacidade de atuação consciente desta conforme seus desejos na busca pela concretização, muito embora objetos e animais humanos e não humanos sejam atingidos por fatores externos.

A independência é relativa à inexistência de influências controladoras das ações do indivíduo, não se podendo afirmar que ele as queira. Isso pode ser percebido quando uma pessoa está subordinada à ameaça de violência, sendo compelida a evitar prejuízos, por exemplo, em circunstâncias de beligerância, relacionamentos abusivos, pobreza e estado policial. Uma pessoa pode se encontrar em completa ausência ou pouca capacidade de autonomia frente a atitudes manipuladoras e de coerção implacável, 
de modo que resultem condutas dirigidas aos outros, autoimagens, planos e crenças que restringem seu campo de opções, presentes notadamente em sociedades escravocratas, totalitárias e de castas. Uma pessoa pode sofrer coerção, manipulação, persuasão e limitações de ambientes físicos e sociais (MILLER, 2004, p. 246).

A racionalidade, ou seja, a capacidade para a tomada racional de decisões, por seu turno, é medida pela resposta pessoal frente a crenças e mudanças, em que se avalia a habilidade no reconhecimento, reflexão, tomada de decisões e opções alternativas. A racionalidade também pode ser medida pela forma de refletir sobre os desejos. Assim os psicopatas, esquizofrênicos, neuróticos compulsivos e paranoicos são doentes mentais severos que possuem ausência de capacidade psicológica para a tomada racional de decisões, embora detenham capacidade de atuação de acordo com os seus desejos (MILLER, 2004, p. 246-247).

Portanto para que o paciente possa elaborar as diretivas antecipadas de vontade, especialmente o testamento vital precisa ter presente autoconsciência dos seus desejos, não sofrer influências externas, tomar as decisões de forma independente e racional, refletindo sobre seus desejos. Nesse sentido, não há uma regra geral que permita que determinados pacientes possam exprimir sua vontade ou não, isso depende dos fatores já citados, mas também de outros. Os outros fatores relacionam-se à legislação, como o Código Civil, o Estatuto da Pessoa com Deficiência (Lei 13.146/2015) e as orientações emitidas pelo Conselho Federal de Medicina.

No que se relaciona ao Código Civil, percebe-se que é progressivo e paulatino o processo de aquisição da maturidade. No Código Civil de 2002, nos artigos $3^{\circ}, 4^{\circ}$ e $5^{\circ}$, o desenvolvimento infanto-juvenil parte dos absolutamente incapazes para os atos da vida civil, que são os menores de 16 anos de idade, passando pelos relativamente incapazes, os que se encaixam entre 16 e 18 anos de idade, até alcançar a maioridade, aos 18 anos de idade, quando a pessoa é considerada pronta para exercer todos os atos da vida civil.

Antes da Lei $\mathrm{n}^{0}$ 13.146/2015, do Estatuto da Pessoa com 
As Diretivas Antecipadas de Vontade em Transtornos Mentais...

Deficiência, o artigo $3^{\mathrm{o}}$ incluía, em seu rol de absolutamente incapazes, os deficientes mentais e os enfermos que não tivessem o necessário discernimento para a prática dos atos da vida civil. No artigo $4^{\circ}$, entre os relativamente incapazes e ao lado dos ébrios habituais e dos viciados em tóxicos, estavam as pessoas com deficiência mental, com discernimento reduzido e os excepcionais sem desenvolvimento mental completo. Naquele momento, as pessoas portadoras de transtornos mentais poderiam, dependendo da interpretação do Código, ser consideradas relativamente incapazes. Dessa forma a criação de um testamento vital não seria possível, já que estes indivíduos não poderiam responsabilizar-se sozinhos por uma questão de tamanha importância, teriam que ser assistidos por seus curadores. Em relação ao mandato duradouro, por tratar-se de indicação de uma pessoa de confiança para tomada de decisões nos últimos momentos de existência do indivíduo, seria até possível, mas com limitações.

$\mathrm{O}$ atual Código Civil estabelece que os indivíduos incapazes absolutos são destituídos de qualquer discernimento, necessitando de representação legal. Depois dos 16 anos, são enquadrados entre os relativamente incapazes, em vista da redução do seu discernimento, precisando ser assistidos por representante legal. A partir do Estatuto da Pessoa com Deficiência (Lei 13.146/2015), todavia, a pessoa com deficiência mental e o enfermo são compreendidos entre os plenamente capazes, aferindo a absoluta incapacidade tão somente aos menores de 16 anos de idade.

O artigo $6^{\circ}$ do Estatuto da Pessoa com Deficiência (Lei 13.146/2015) inclui como capazes os enfermos, os deficientes mentais e os excepcionais. Dessa forma, o Estatuto da Pessoa com Deficiência reafirma a capacidade plena das pessoas que possuem algum transtorno mental. Além disso, a referida lei em seu art. 11 deixa claro que as intervenções clínicas e cirúrgicas, tratamentos e institucionalização não poderão ocorrer sem o consentimento da pessoa com deficiência. É claro que se deve levar em conta o grau de deficiência do paciente, seja leve, moderado ou grave. Se for leve, e a 
pessoa possuir condições de discernir sobre sua situação e os tratamentos oferecidos, não há impedimento para que elabore diretivas. Se a deficiência for moderada pode ser adotado o procedimento de decisão apoiada e se for grave será caso de curatela (DIAS; SILVA JUNIOR, 2019). Na sequência o art. 12, determina a imprescindibilidade do recolhimento do consentimento prévio, livre e esclarecido, caso a pessoa com deficiência necessite de algum procedimento, tratamento, hospitalização ou se submeta à pesquisa científica. O parágrafo único assegura a maior participação possível ao deficiente curatelado no processo de coleta da manifestação do consentimento, que é dispensada se a pessoa com deficiência estiver sob risco de morte e em situação emergencial, devendo ser respeitados os seus interesses e as normativas legais (BRASIL, 2015b).

O Conselho Federal de Medicina, na Resolução no 1.995/2012, art. $2^{\mathrm{o}}, \S 1^{\mathrm{o}}$ e $\S 2^{\mathrm{o}}$, no tocante aos pacientes incapazes de se comunicarem, ou que não consigam manifestar livre e independentemente suas vontades, estabelece que o médico deva considerar as diretivas antecipadas de vontade, no momento de decidir sobre cuidados e tratamentos, acatando, inclusive, as informações relatadas pelo representante do paciente, caso este tenha designado previamente, salvo se essas diretrizes não estiverem de acordo com as determinações prescritas no Código de Ética Médica. A Resolução, destarte, não exige obrigatoriamente que os desejos do representante sejam atendidos, mas que sejam levados em consideração.

O Código de Ética Médica proíbe as terapias inúteis e obstinadas (distanásia) e orienta os médicos a praticarem cuidados paliativos em face de paciente terminal ou acometido de doença incurável. Não obstante, o médico pode deixar de atender às diretrizes do paciente caso elas sejam incompatíveis com o Código de Ética, ou seja, o limite para as diretivas está na hipótese de atendimento de pacientes que possam ser salvos, prevalecendo, neste aspecto, a autonomia do médico (CFM, 2013; REVISTA 
As Diretivas Antecipadas de Vontade em Transtornos Mentais...

ANOREG/SP, 2012, p. 24-29).

A dificuldade enfrentada pelo médico restaria para aqueles casos em que exista deficiência grave impeditiva de manifestação de vontade sobre tratamento e hospitalização, sem que se esteja em situação emergencial de risco de morte e que nunca puderam deixar registrados seus desejos, ou que o fizeram, mas evoluiu com agravamento da enfermidade.

Percebe-se por meio destas reflexões que de acordo com o Código Civil e com o Estatuto da Pessoa com Deficiência, o paciente psiquiátrico teria condições de manifestar sua vontade para os momentos finais de sua vida, já que não consta no rol de incapazes. No entanto, é preciso que se atente às condições de autonomia psicológica do paciente, verificando se o mesmo está em condições adequadas de saúde mental para criar diretivas antecipadas de vontade. Nesse sentido, entendendo que é possível a criação das diretivas, deve-se verificar a sua viabilidade no que se relaciona ao paciente com transtorno mental severo em situações não emergenciais.

\section{VIABILIDADE CONCRETA DAS DIRETIVAS \\ PSIQUIÁTRICAS DE VONTADE PARA PACIENTES COM TRANSTORNOS MENTAIS SEVEROS EM SITUAÇÃO NÃO EMERGENCIAL}

De acordo com Dias e Silva Junior (2019), as diretivas antecipadas são comumente utilizadas nos casos de pacientes terminais, que buscam previamente definir os tratamentos a que serão submetidos. Mas também, podem ser úteis para portadores de transtornos mentais, adotando-se medidas para momentos em que não se possuirá discernimento para tomar decisões. Os autores verificam que essa prática ocorre com muita frequência em países 
anglo-saxões, em que há instrumentos que tem como objetivo proteger o paciente da psiquiatria, definindo previamente os tratamentos que serão adotados e impedindo determinadas condutas médicas, com as quais o paciente não concorda. Porém os autores questionam: como saber se o paciente está em condições de decidir se necessita ou não de tratamento?

Esta questão de difícil resposta vem sendo debatida nos Estados Unidos da América, na Carolina do Norte, desde 1980. Desde esta data vigoram as diretivas antecipadas psiquiátricas (SWANSON et al., 2006, p. 385). Essas diretivas são compostas de instruções de saúde mental, e de um representante com função decisória. Essas peças podem vir separadas ou acumuladas em um único instrumento, objetivando recusar ou consentir tratamentos durante uma possível crise mental vindoura.

É importante destacar que existem três modalidades de diretivas antecipadas em saúde mental: instructional directives, proxy directives e hybrid directives. Nas instructional directives, o paciente em um momento de lucidez comunica as instruções a serem seguidas para quando se encontrar em uma situação de crise e incompetente para decidir a respeito dos tratamento a que será submetido. Já no caso das proxy directives, o paciente nomeia um curador para tomar decisões em seu lugar, quando se encontrar em situações de incompetência, o que se assemelha ao mandato duradouro. Por fim, as hybrid directives ou diretivas híbridas combinam a nomeação do procurador com estabelecimento de medidas à serem adotadas por ele (DIAS; SILVA JUNIOR, 2019).

Porém o estabelecimento das diretivas antecipadas de vontade para pacientes psiquiátricos, em qualquer das modalidades apresentadas carrega discussões éticas relevantes. Isso ocorre especialmente quando o médico não concorda com as decisões tomadas pelo paciente. Nesse caso, como proceder? Conforme a instrução legal das diretivas antecipadas psiquiátricas na Carolina do Norte, o médico tem livre arbítrio caso sua forma de tratamento desarmonize com a escolha feita pelo paciente antecipadamente e 
As Diretivas Antecipadas de Vontade em Transtornos Mentais...

esteja fora dos padrões de cuidado. Além disso, se o médico estiver imbuído de boa-fé, e sua conduta estiver ajustada aos padrões clínicos, lhe é facultado rejeitar, parcial ou totalmente, as diretivas, tendo o privilégio da imunidade legal. Em princípio, os médicos devem cumprir o máximo possível as diretivas antecipadas do paciente, quando houver (SWANSON et al., 2006, p. 386).

No Estado da Pensilvânia, em 30 de janeiro de 2005, entrou em vigor a Lei $\mathrm{n}^{\circ} 194$, regulamentando as diretivas antecipadas e os poderes do representante legal do requerente. A norma daquele Estado reitera o estabelecido no Federal Patient Self-Determination, da década de 1990, mas faculta aos médicos dispensarem as diretivas em três situações:

a) se elas atrapalharem a admissão de pacientes com problemas mentais em estabelecimento de saúde mental, de acordo com o regulamento previsto na Lei de Procedimentos de Saúde Mental;

b) em caso de diretivas estatuindo condutas contrárias aos padrões médicos clínicos, e o médico se recusar a segui-las, deverá envidar esforços para transferir o paciente para outro médico, mas se fracassar na tentativa de transferência, poderá dispensar o paciente ficando imunizado pelo documentado nas diretivas; e

c) o médico que se recusar a atender às diretivas, porém atuar de boa-fé, não se sujeita à responsabilidade civil, criminal ou disciplinar pelo simples fato de se recusar a seguir as diretivas (SWANSON et al., 2006, p. 385).

Em um estudo realizado por Brock (1991, apud Swanson et al., 2006, p. 387-388), constataram-se três possíveis justificativas ao médico para arredar as disposições do paciente:

a) quando o médico não conseguir precisar os desejos do paciente constantes nas diretrizes;

b) quando a conduta moral do paciente no presente entrar em conflito com a moral registrada nas diretrizes;

c) quando os interesses de outras pessoas forem superiores (e que justificam não honrar as diretrizes). 
Em resposta à primeira justificativa, de que as pessoas com deficiência mental persistente não conseguem estabelecer uma comunicação que possibilite manifestar suas escolhas e que há certas deficiências psiquiátricas que jamais permitirão ao paciente analisar o que é melhor para si, Swanson et al. (2006, p. 387-388) reagiram com o contra-argumento: de que há uma categoria de pacientes psiquiátricos que podem escolher tratamentos por conhecerem os efeitos negativos e positivos em razão do tempo prolongado em que foram expostos a eles pela hospitalização recorrente. Já os que desconhecem essa experiência, poderão enfrentar tais problemas.

Relativamente à segunda justificativa, os professores concordam que existam pacientes que podem não transmitir sua identidade pessoal de modo que haja conflito de interesses entre as diretrizes pretéritas, ou seja, escolhidas anteriormente, e os desejos atuais do paciente. Nesse caso, o melhor é afastar as diretivas anteriores e acatar as manifestações presentes do paciente. Alguns médicos acreditam que a mera situação de desordem crônica capaz de desajustar a percepção, julgamento e pensamento já tornam inválidas as diretrizes antecipadas. Pode acontecer de coincidir uma psicopatologia com uma deficiência cognitiva, por um longo período de tempo, alterando a personalidade da pessoa, o que dificulta ao médico identificar a real identidade do paciente. Alguns estados psicóticos podem levar pacientes a buscar o suicídio, o que pode trazer para a discussão a segurança deles, colocando em questão a validade das diretivas.

Para a terceira justificativa, Swanson et al. (2006, p. 388-389), posicionaram-se dizendo que pode acontecer de os interesses do paciente serem irrelevantes quando comparados aos interesses da família, dos médicos ou da sociedade em geral. No caso dos médicos, é possível que eles entendam que tratamentos de sustentação vital sejam fúteis, apesar do posicionamento contrário do próprio paciente registrado nas diretivas e da família optando pela manutenção da terapia.

Em outro estudo realizado por Swanson e McCrary (1996, 
As Diretivas Antecipadas de Vontade em Transtornos Mentais...

apud Swanson et al. 2006, p. 388-389), em que entrevistaram 301 médicos no Texas, concluiu-se que existem médicos que agem de forma extremamente defensiva e legalista, a ponto de se preocuparem mais em distinguir um tratamento fútil de uma terapia vantajosa de forma arbitrária ampliando a sua esfera de atuação do que realmente importarem-se com a opinião do paciente em relação a formas de tratamento em fim de vida. Essa atitude colabora para trazer conflitos com os pacientes. Ademais, os médicos tendem a agir defensivamente por receio das responsabilidades legais pelas possíveis consequências desvantajosas resultantes do cumprimento das diretrizes do paciente, como, por exemplo, a hipótese de um paciente externar um comportamento violento se não tratado. Outra pressão externa sofrida pelo médico é a social e que se vê obrigado a realizar o tratamento a despeito da recusa antecipada do paciente (SWANSON et al., 2006, p. 388-389).

Ademais, o médico também pode se deparar com um paciente que vem se tratando, mas os efeitos das terapias são insatisfatórios ou piorados, de tal modo que o próprio paciente recuse antecipadamente essas terapêuticas, por exemplo, a recusa de um medicamento antipsicótico (SWANSON et al., 2006, p. 390).

Contudo, o raciocínio ético e prático do psiquiatra pode levá-lo a não acatar a recusa antecipada do paciente, insistindo em administrar um novo medicamento, ainda que mais caro, mas com melhores efeitos sintomáticos, julgando que os profissionais de saúde mental, inclusive de todo o sistema de cuidado de saúde mental, são de certa forma responsáveis pelas desastrosas experiências sofridas pelos pacientes que se submeteram a esses tratamentos e que essas experiências adversas ajudaram a estimular a rejeição do paciente pelos tratamentos que foram incapazes de aliviar as crises. Isso demonstra distorção da preferência resultante da má informação tida pelo paciente que precisa tomar conhecimento de medicamentos que o psiquiatra acredita terem bons resultados - isso levaria o médico a não acatar a recusa antecipada (SWANSON et al., 2006, p. 390).

Diante dessas questões, qual seria o real benefício da 
elaboração das diretivas antecipadas de vontade para o paciente com transtorno mental? Dias e Silva Junior (2019), apontam como benefícios, a ampliação da autonomia, melhora nas relações com os familiares, aumento da aceitação dos prestadores de serviço em saúde quanto à autonomia do pacientes, redução de atendimentos médicos e admissão em serviços hospitalares, bem como de internações compulsórias. No entanto, os autores alertam a respeito da necessidade de estudos empíricos sobre o tema para determinar se tais benefícios estão presentes. Afirmam que os estudos mais recentes (CAMPBELL, KISELY, 2009 e MAÎTRE ET ALLI, 2013) orientam a adoção de medidas conjuntas de planejamento para situações de crise (joint crisis planning), com a participação de pacientes e familiares como melhor modelo de diretiva a ser adotado. A discussão desse modelo de diretiva psquiátrica que envolva pacientes e familiares pode ser relevante no Brasil, considerando as dificuldades existentes no que se relaciona ao tratamento em saúde mental no país.

No Brasil essas dificuldades foram verificadas em um estudo realizado em 2011, por Cardoso et al. (2011, p. 1-9), em um núcleo de saúde mental, que visava aferir o grau de adesão de 48 pacientes egressos de internação psiquiátrica ao tratamento psicofarmacológico. Verificou-se que 70 por cento deles foram escalonados como baixo grau de adesão ao tratamento. Ademais, tão somente 21 conseguiram transmitir qual era o seu diagnóstico sendo que, destes, a maioria não logrou dizer sobre o nome e a dosagem dos medicamentos prescritos de forma parcial ou completa.

Segundo Cardoso et al. (2011, p. 1-9), a adesão ao tratamento ajuda a diminuir os riscos de recaídas e de internações. As causas para baixa adesão são adversas: custo dos medicamentos, interação medicamentosa, inadequada educação em saúde, não compreensão das instruções, relação médico-paciente e serviços de saúde deficientes. Em razão do baixo grau de instrução, os pacientes não compreendem sobre o tempo da doença e sobre a prescrição dos medicamentos, levando à persistência dos transtornos graves. 
As Diretivas Antecipadas de Vontade em Transtornos Mentais...

Verificou-se também que os pacientes não tomam os medicamentos quando sentem alguma melhora e se esquecem de ingeri-los ou descuidam-se quanto aos horários adequados, malefícios ao próprio paciente de tal modo que compromete o seu desenvolvimento crítico. Os estudos mostraram a inexistência de programas que ajudam na identificação de doenças de transtornos mentais, de modo que o início da doença é caracterizado por muitos conflitos de ordem cognitiva, familiar, levando o indivíduo ao isolamento, dificuldade de atenção e concentração (CARDOSO et al., 2011, p. 1-9).

Considerando todas as dificuldades apontadas para a concretização do exercício de autonomia pelos pacientes psiquiátricos, especialmente no que se relaciona a criação de diretivas antecipadas, seria possível o exercício de disposição da própria vida por estes pacientes no Brasil? Esta questão tem uma resposta complexa, porém o que se pode afirmar é que a aquisição da autonomia desses pacientes parece restar apenas no campo teórico frente à complexidade das doenças e à deficitária assistência doméstica, escolar e social. O baixo grau de adesão ao tratamento denota o quão distante se está da concretização das diretivas psiquiátricas de vontade. Porém deve-se reconhecer que as pessoas com transtorno mental, assim como as pessoas com deficiência tem o direito ao exercício de sua capacidade legal, em igualdade de condições com as demais pessoas, o que inclui a possibilidade de emitir diretivas antecipadas (DIAS; SILVA JUNIOR, 2019) e, portanto deve-se avançar nesse sentido, especialmente no que se refere a pesquisas empíricas sobre o tema no país, incluindo-se a questão da elaboração conjunta de diretivas antecipadas de vontade. 


\section{CONCLUSÃo}

No intuito de valorizar a autonomia e a autodeterminação do paciente, quando da tomada de decisão sobre tratamentos de saúde, as diretivas antecipadas de vontade foram desenvolvidas para se deixar registrado, previamente, as disposições de vontade do paciente em relação à terapêutica necessária em momento vindouro, envolvendo toda a equipe assistencial e os familiares do paciente.

Maior dificuldade restaria para aqueles casos em que o paciente seja acometido de transtorno mental grave impeditivo de manifestação de vontade sobre tratamento e hospitalização, em situações de não urgência ou emergência, e que não existem diretivas antecipadas para o médico se apoiar, ou que a patologia tenha se agravado de tal modo que não se ajustam mais àqueles desejos previstos no documento.

Da análise das pesquisas utilizadas neste artigo, verificou-se que: a) em princípio, havendo as diretivas, os médicos devem cumpri-las o máximo possível; b) a conduta escolhida pelo paciente deve estar ajustada aos padrões clínicos e éticos; c) as diretivas podem ser desconsideradas quando não se conseguir identificar a vontade do paciente claramente, sempre buscando a segurança do paciente e de outras pessoas; d) o agravamento da doença com o tempo; e) que, em muitos casos, os pacientes já conhecem os efeitos negativos do tratamento e demonstram rejeitá-los, cabendo ao médico ponderar essas situações aconselhando a família a respeitar as manifestações do paciente; f) cuidado com os efeitos colaterais das interações medicamentosas; g) adequação dos medicamentos às condições financeiras do paciente; h) orientação ao paciente sobre sua enfermidade, riscos e manutenção do tratamento.

Desse modo, conclui-se que há dificuldades para a realização das diretivas psiquiátricas, devido à limitada autonomia dos pacientes, o baixo grau de adesão ao tratamento e a assistência deficitária. No entanto, as diretivas antecipadas psiquiátricas tem 
As Diretivas Antecipadas de Vontade em Transtornos Mentais...

potencial para serem realizadas, considerando o direito que a pessoa tem de decidir a respeito dos tratamentos a que será submetida. Devem ser seguidas pela equipe médica desde que não coloquem em risco a vida do paciente e dos cuidadores, e que não violem os preceitos médicos, éticos e legais, cabendo ao médico avaliar cada caso em particular. Interessante seria avançar em relação à criação dessas diretivas com a participação de familiares, ou seja, por meio da elaboração conjunta, nesse sentido, sugerem-se pesquisas de caráter empírico sobre o tema.

Data de Submissão: 23/08/2018

Data de Aprovação: 06/04/2019

Processo de Avaliação: double blind peer review

Editor Geral: Jailton Macena de Araújo

Editor de Área: Fernando Joaquim Ferreira Maia

\section{REFERÊNCIAS}

ALVES, C. A.; FERNANDES, M. S.; GOLDIM, J. R. Diretivas antecipadas de vontade: um novo desafio para a relação médicopaciente. In: Revista HCPA/Hospital de Clínica de Porto Alegre, Porto Alegre, v. 32, n. 3, p. 358-362, 2012.

ASSOCIAÇÃO AMERICANA DE PSQUIATRIA. Manual diagnóstico e estatístico de transtornos mentais: DSM 5. Tradução Maria Inês Corrêa Nascimento. 5 ed. Porto Alegre: Artmed, 2014.

BRASIL. Código 3 em 1: Penal, Processo Penal e Constituição Federal: obra coletiva com a colaboração de Luiz Roberto Curia, Lívia Cespedes e Juliana Nicoletti. 11. ed. São Paulo Saraiva, 2015a.

BRASIL. Código Civil: Lei n. 10.406, de 10 de janeiro de 2002. São Paulo: Revista dos Tribunais, 2002.

BRASIL. Senado Federal. Estatuto da pessoa com deficiência: lei brasileira de inclusão n. 13.146, de 06 de julho de 2015. Brasília: Senado Federal, 2015b. 
CAMPBELL LA, KISELY SR. Advance treatment directives for people with severe mental illness. Cochrane Database Syst Rev. v.21, 2009.

CARDOSO, L. et al. Grau de adesão e conhecimento sobre tratamento psicofarmacológico entre pacientes egressos de internação psiquiátrica. In: Revista Latino-Americana Enfermagem, v. 19, n. 5, 9 telas, set./out. 2011. Disponível em:

<http://www.scielo.br/pdf/rlae/v19n5/pt_12.pdf>. Acesso em: 14 jun. 2017.

CFM - Conselho Federal de Medicina. Código de Ética Médica. Resolução n. 1.931/2009. In: FRANÇA, Genival Veloso. Direito médico. 11. ed. rev., atual. e ampl. Rio de Janeiro: Forense, 2013.

CFM - Conselho Federal de Medicina. Resolução n. 1.805/2006. Disponível em:

<http://www.portalmedico.org.br/resolucoes/cfm/2007/111_2007.h tm>. Acesso em: 06 jul. 2015.

CFM - Conselho Federal de Medicina. Resolução n. 1.995/2012. Dispõe sobre as diretivas antecipadas de vontade dos pacientes. Disponível em: <http://www.portalmedico.org.br/resolucoes/CFM/2012/1995_201 2.pdf $>$. Acesso em: 6 jul. 2015.

CNBSP - Colégio Notarial do Brasil - Seção São Paulo. Testamento vital permite ao paciente decidir que tratamento médico terá. 30 nov. 2015. Disponível em:

<http://www.cnbsp.org.br/index.php?pG=X19leGliZV9ub3RpY2lhc $\mathrm{w}==$ \&in=MTEyMDM=\&filtro=> . Acesso em: 14 mar. 2016.

CORREGEDORIA GERAL de Justiça do Estado de Minas Gerais. Provimento 26o/CGJ/2013. Publicação em 30 out. 2013. Disponível em:

<http://www8.tjmg.jus.br/institucional/at/pdf/cpro2602013.pdf>. Acesso em: 08 abr. 2016.

DIAS, E.R.; SILVA JUNIOR, G.B. Autonomia das pessoas com transtorno mental, diretivas antecipadas psiquiátricas e contrato de Ulisses. Revista Jurídica Luso-Brasileira, Lisboa, n. 1, p. 519-545, 2019.

ESTADO DE SÃO PAULO. Lei estadual n. 10.241, de 17 de março de 1999. Dispõe sobre os direitos dos usuários dos serviços e das ações de saúde no Estado e dá outras providências. São Paulo, 1999. Disponível em:

<http://www.pge.sp.gov.br/centrodeestudos/bibliotecavirtual/dh/vo lume\%20i/saudelei10241.htm>. Acesso em: 10 set. 2015.

ESTADO DO RIO GRANDE DO SUL. Tribunal de Justiça. Apelação Cível n. 70042509562/2011. Associação dos funcionários públicos do 
As Diretivas Antecipadas de Vontade em Transtornos Mentais...

ERGS - AFPERGS, apelante, e Gilberto Oliveira Freitas e Guilherme da Silva Benites, apelados. 01 jun. 2011. Desembargador Armínio José Abreu Lima da Rosa (Presidente e Relator).

ESTADO DO RIO GRANDE DO SUL. Tribunal de Justiça. Apelação Cível n. 70054988266 (n. CNJ: 0223453-79.2013.8.21.700O).

Ministério Público, apelante, e João Carlos Ferreira, apelado. 20 nov. 2013. Desembargador Irineu Mariani (Relator).

GAUW, J.H.; ALBUQUERQUE, A.L.A.; LINS, I.K.F.G.; CHAVES, J.H.B. Diretivas antecipadas de vontade: a necessidade de um maior conhecimento desde a graduação. Revista Científica da FMC, Campos, v.12, n.1, 2017.

GOUVEIA, L.R. Diretivas antecipadas de vontade - testamento vital: aplicação do fundamento constitucional da dignidade da pessoa humana. Revista Eletrônica da Faculdade de Direito de Franca, Franca, v. 12, n.2, p. 149-208, 2017.

INSTITUTO BRASILEIRO de Direito de Família. Após regulamentação cresce $690 \%$ o número de testamentos vitais no Brasil. Colégio Notarial do Brasil - Seção São Paulo. 11 ago. 2015. Disponível em:

<http://ibdfam.org.br/noticias/5717/Ap\%C3\%B3s+regulamenta\% C3\%A7\%C3\%A30\%2C+cresce+690\%25++o+n\%C3\%BAmero+de+tes tamentos+vitais+lavrados+no+Brasil>. Acesso em: 14 mar. 2016.

MAÎTRE E , DEBIEN C, NICAISE P, WYNGAERDEN F, Le GALUDEC M, GENEST P, DUCROCQ F, DELAMIL-LIEURE P, LAVOISY B, WALTER M, DUBOIS V, VAIVA G. Advanced directives in psychiatry: a review of the qualitative literature, a state-of-the-art and view-points. L'Encéphale, v. 39, n.4, p. 244-251, 2013.

MANSUR, A.; MARQUES, F. Carcinomatose meníngea: caso Mário Covas. Revista Época, 15 abr. 2011. Disponível em:

$<$ http://carcinomatosemeningea.blogspot.com.br/2011/o4/casomario-covas.html>. Acesso em: 12 abr. 2016.

MILLER, B. Autonomy. In: POST, S. Encyclopedia of Bioethics. 3. ed. New York: Macmillan, 2004. p. 246-251.

MINISTÉRIO PÚBLICO FEDERAL. Ação Civil Pública $n$. ooo1103986.2013.4.01.350o. Brasília, 21 fev. 2014. Disponível em: <http://www.prgo.mpf.gov.br/images/stories/ ascom/ACP-CFMortotanásia.pdf $>$. Acesso em: 06 jul. 2015.

MUSTAFA, A. Enfim, descanse em paz. CREMESP - Conselho Regional de Medicina do Estado de São Paulo, 6 dez. 2010, Diário de São Paulo. Disponível em:

<http://www.cremesp.org.br/?siteAcao=Imprensa\&acao=crm_midi a\&id=589>. Acesso em: 12 abr. 2016. 
PITTELLI, S. D. Resolução CFM n. 1995/2012: diretivas antecipadas. Revista Visão Médica, Hospital Alemão Oswaldo Cruz, ed. 14, p. 136, jan./fev./mar. 2013 .

PITTELLI, S. D.; OLIVEIRA, R. A. de. Eutanásia e sua relação com casos terminais, doenças incuráveis, estados neurovegetativos, estados sequelares graves ou de sofrimento intenso e irreversível e morte encefálica. Revista Saúde, Ética \& Justiça, v. 14, n. 1, p. 32-39, 2009.

REVISTA ANOREG/SP. Cartório hoje: serviços de cartório na internet, n. 3, p. 24-29, dez. 2012.

SERRANO, S. C. Pesquisa em cuidados paliativos. Revista Brasileira em Cuidados Paliativos, São Paulo, v. 3, n. 4, p. 7-8, 2012.

SWANSON, J. et al. Superseding psychiatric advance directives: ethical and legal considerations. The Journal of the American Academy of Psychiatry and the Law, v. 34, n. 3, p. 385-394, 2006.

V JORNADA DE DIREITO CIVIL. Ministro Ruy Rosado de Aguiar Jr. (Org.). Brasília: CJF, 2012.

XEREZ, R.M.; PINTO, H.C. A (in)dignidade nos direitos à vida e à morte em casos de doenças terminais ou pacientes em coma a partir do filme“ Bella Addormentata”. Prim@ Facie, João Pessoa, v.17, n.36, p. 1-26, 2018. 


\title{
The Advance Directives of Will in Mental Disorders with Reflection of Fundamental Right to Freedom: Needed Discussions
}

\author{
Janaína Reckziegel \\ Orides Mezzaroba
}

\section{Beatriz Diana Bauermann Coninck}

\begin{abstract}
This article aims to investigate the concrete feasibility of adherence to the instrument of psychiatric advance directives of will, admittedly a fundamental right, by non-emergency patients with severe mental disorders. In order to do so, general notions will be discussed about advance directives of will, for, in the second item, entering into the study of the psychiatric advance directives of will and, in the third topic, talking about the feasibility of psychiatric advance directives of will. From the investigation made through the deductive method of qualitative approach in national references, including empirical studies, it was discovered that the difficulty in identifying diagnosis of mental disorders by doctors and the problem of adherence to pharmacological treatment by the person suffering mental disorder, are important causes for relapse recurrence of crisis, hospitalizations and chronicity of diseases, and, for consequence, rejection of psychiatric advance directives of will by doctors.
\end{abstract}

Keywords: Fundamental right. Psychiatric advance directives of will. Patients with non-emergency severe mental disorders. 